\title{
Maturation-Stage Ameloblast
}

National Cancer Institute

\section{Source}

National Cancer Institute. Maturation-Stage Ameloblast. NCI Thesaurus. Code C33057.

A short columnar epithelial cell that has deposited enamel and has lost org anic material and water. It deposits calcium and phosphorus into the enamel matrix. The maturationstage ameloblast produces and secretes small amounts of proteins. 